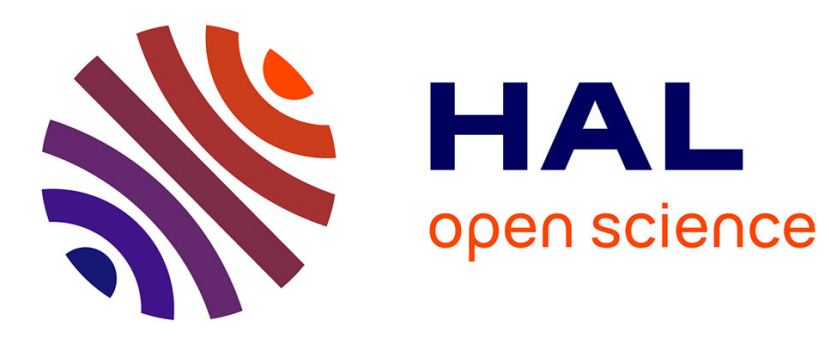

\title{
Influence of the mechanical behaviour specificities of damaged refractory castables on the Young's modulus determination
}

F Nazaret, H Marzagui, Thierry Cutard

\section{- To cite this version:}

F Nazaret, H Marzagui, Thierry Cutard. Influence of the mechanical behaviour specificities of damaged refractory castables on the Young's modulus determination. Journal of the European Ceramic Society, 2006, 26 (8), pp.1429-1438. 10.1016/j.jeurceramsoc.2005.03.231 . hal-01714933

\section{HAL Id: hal-01714933 \\ https://hal.science/hal-01714933}

Submitted on 6 Nov 2018

HAL is a multi-disciplinary open access archive for the deposit and dissemination of scientific research documents, whether they are published or not. The documents may come from teaching and research institutions in France or abroad, or from public or private research centers.
L'archive ouverte pluridisciplinaire HAL, est destinée au dépôt et à la diffusion de documents scientifiques de niveau recherche, publiés ou non, émanant des établissements d'enseignement et de recherche français ou étrangers, des laboratoires publics ou privés. 


\title{
Influence of the mechanical behaviour specificities of damaged refractory
}

\section{castables on the Young's modulus determination}

\author{
F. Nazaret, H. Marzagui, T. Cutard* \\ Research Center on Tools Materials and Processes (CROMeP), Ecole des Mines d'Albi-Carmaux, Campus Jarlard, Route de Teillet, Albi 81000, \\ France
}

\begin{abstract}
This paper deals with the problematic of the determination of the Young's modulus of refractory castables by the way of mechanical tests. Two materials are considered: a cordierite based refractory castable that is reinforced with short steel fibres and an andalusite based refractory castable. Discrepancies in Young's modulus values are noticed depending on whether they are determined on direct tensile test curves, four points bending test curves or compression test curves. Damage due to a first thermal cycle is underlined as enhancing these discrepancies. Original mechanical tests have been performed in order to understand the influence of such a damage on the four points bending and compression behaviours. Results show that depending on the method that is used to measure displacements and strains, the calculated Young's modulus values can be highly influenced by local strain effects that occur at the contact between the sample and the loading system. Related to the damage that develops in these materials during the first heat treatment, these effects are more important when samples have been previously fired.
\end{abstract}

Keywords: Elastic modulus; Mechanical properties; Refractories

\section{Introduction}

In a wide range of industrial applications, refractory castables are subjected to severe solicitations, especially from a thermomechanical point of view. Previous studies have already been performed in the field of the high temperature behaviour of refractory castables. ${ }^{1-7}$ Nevertheless, they have been less studied than engineering ceramics ${ }^{1}$ and there is still a need in obtaining high temperature mechanical behaviour curves and in developing constitutive laws for these materials. This is particularly true to develop numerical simulation approaches in order to improve the design and the service life duration of structures that are based on refractory castables. Bending tests are easy to perform at high temperature and are largely used to study refractory castables. But, it remains difficult to develop constitutive laws from their results. This is mainly due to the non-linear behaviour of these materials

\footnotetext{
* Corresponding author. Tel.: +33 5634931 61; fax: +33 563496099 .

E-mail addresses: nazaret@enstimac.fr (F. Nazaret), marzagui@enstimac.fr (H. Marzagui), cutard@enstimac.fr (T. Cutard).
}

and to the dissymmetry that is classically observed between the tensile and compression behaviours. In order to be able to obtain behaviour curves under these two loading modes, high temperature tensile tests and compression tests are now under development. ${ }^{1,8}$ This paper deals with the comparison of the Young's modulus values that can be obtained from the three considered test types. Large differences can be obtained, even if the Young's modulus is normally an intrinsic property of the tested materials. Such observations have already been made by several authors who have performed two types of mechanical tests at least..$^{5-7,9,10}$ In this paper, an explanation of these Young's modulus discrepancies is proposed by considering the results of classical and of complementary original mechanical tests that have been made on two refractory castables.

As for as the paper structure is concerned, the compositions and the processing routes of the two considered materials are first given, as well as a description of the experimental devices that are used. Then, results of conventional tensile tests, four points bending tests and the compression tests are briefly presented. More attention is paid to the determination 
of the Young's modulus. The discrepancy phenomenon that is observed between the Young's modulus values is particularly underlined. It is then established that this phenomenon is enhanced for the materials that have been previously fired at high temperature. The cases of four points bending tests and of compression tests are presented and discussed successively. Causes of the differences between the Young's modulus values are exposed and explained.

\section{Materials and experimental methods}

\subsection{Presentation of the refractory castables}

Two refractory castables are considered in the present paper. One of these materials (FRRC) is a geopolymer based refractory castable that is reinforced with 1.5 vol.\% of metallic fibres. It is made of a geopolymer based matrix and of cordierite aggregates. The matrix is obtained by mixing a major alumino-silicate oxide, thermal silica fume and an aqueous solution of potassium polysilicate. ${ }^{11}$ Concerning aggregates, a mixture of four granulometric ranges of a cordierite grog is performed with a maximum aggregate size close to $3 \mathrm{~mm}$. Metallic fibres are made of an AISI 310 stainless steel and are processed by cold drawing. They are characterized by a $0.38 \mathrm{~mm}$ diameter and by a $12.5 \mathrm{~mm}$ length. The FRRC refractory castable is shaped by mixing these different components during $5 \mathrm{~min}$ in a planetary mixer and by casting the mix under vibrations. The vibration amplitude is controlled to remain constant and the vibration time is of $10 \mathrm{~min}$. Complete polymerisation of the matrix is obtained after an isothermal heat treatment of $12 \mathrm{~h}$ at $80^{\circ} \mathrm{C}$. The material is then fired at high temperature in order to stabilize the microstructure for high temperature applications. Such heat treatments are known to generate damage in the FRRC microstructure, mainly because of the differential dilatometric behaviours of the matrix, of the aggregates and of the metallic fibres. ${ }^{12,13}$ Three firing temperatures are considered for this material: 110,500 and $900^{\circ} \mathrm{C}$. Examples of damage which is generated by first heat treatments are given in Figs. 1 and 2. Damage mechanisms deal with aggregate/matrix decohesions, fibre/matrix decohesions and with matrix microcracking too. In the considered temperature domain, the higher the firing temperature is, the higher the damage level is.

The second material (And-LCC) is a commercial grade of a low cement andalusite based castable made of andalusite aggregates, silica fume, alpha-alumina and of a calcium aluminate cement. The samples are prepared by mixing the raw materials in a planetary mixer with a $5 \mathrm{wt} . \%$ water addition and during $5 \mathrm{~min}$. The mix is then cast in the moulds on an amplitude controlled vibration table and during $2 \mathrm{~min}$. Moulds and samples are then immediately wrapped in plastic. They are cured at room temperature during $24 \mathrm{~h}$ and then extracted from the moulds before a $110^{\circ} \mathrm{C}-24 \mathrm{~h}$ drying step. As for the FRRC castable, high temperature heat treatments are known to develop damage in this And-LCC castable. Previous works

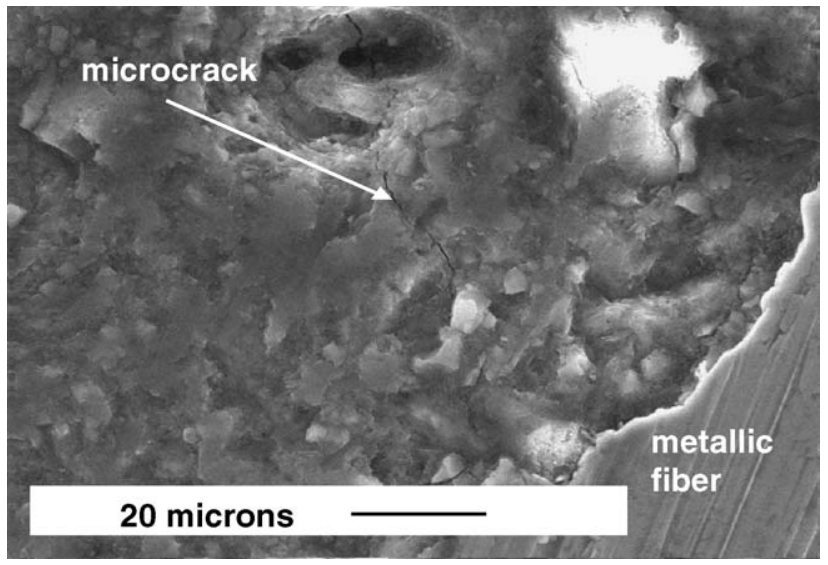

Fig. 1. Observation of damage in the FRRC castable after drying at $110^{\circ} \mathrm{C}$ (scanning electron microscopy).

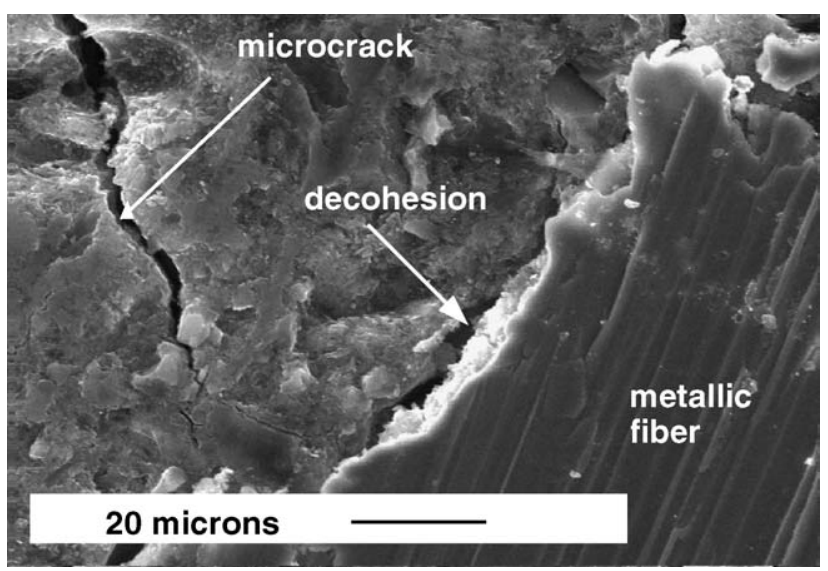

Fig. 2. Observation of damage in the FRRC castable after firing at $500{ }^{\circ} \mathrm{C}$ (scanning electron microscopy).

have shown that this particularly true for firing temperatures that are in the $110-900^{\circ} \mathrm{C}$ temperature range. ${ }^{14,15}$ As these results have shown that firing this material at $700{ }^{\circ} \mathrm{C}$ leads to an important damage state in the microstructure, this firing temperature level will be considered in the present paper for this And-LCC castable. Figs. 3 and 4 enable us to observe the damage mechanisms that have occurred in this material after a $700{ }^{\circ} \mathrm{C}$ heat treatment. They deal again with aggregate/matrix decohesions and with matrix microcracking. They are mainly due to the differential dilatometric behaviour between the matrix and the aggregates. The case of the $110^{\circ} \mathrm{C}$ dried AndLCC castable will be considered in that paper too.

\subsection{Experimental methods}

\subsubsection{Uniaxial tensile test}

Uniaxial tensile tests are performed on a MTS 810 servohydraulic universal testing machine by the way of a nonarticulated tensile system (Fig. 5). Sample extremities are glued on metallic plates that are water-cooled. At high temperature, the central part of the specimen is placed in a MTS 


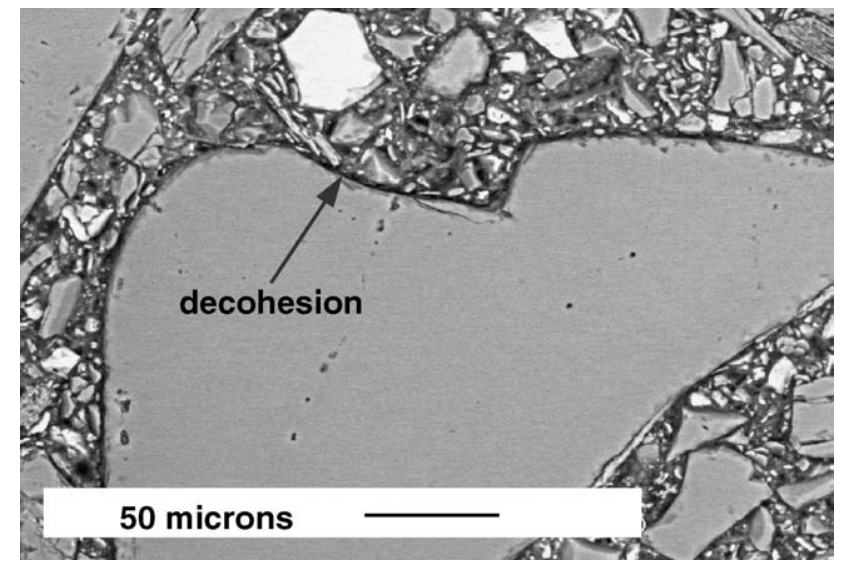

Fig. 3. Observation of damage in the And-LCC castable after firing at $700{ }^{\circ} \mathrm{C}$ (scanning electron microscopy).

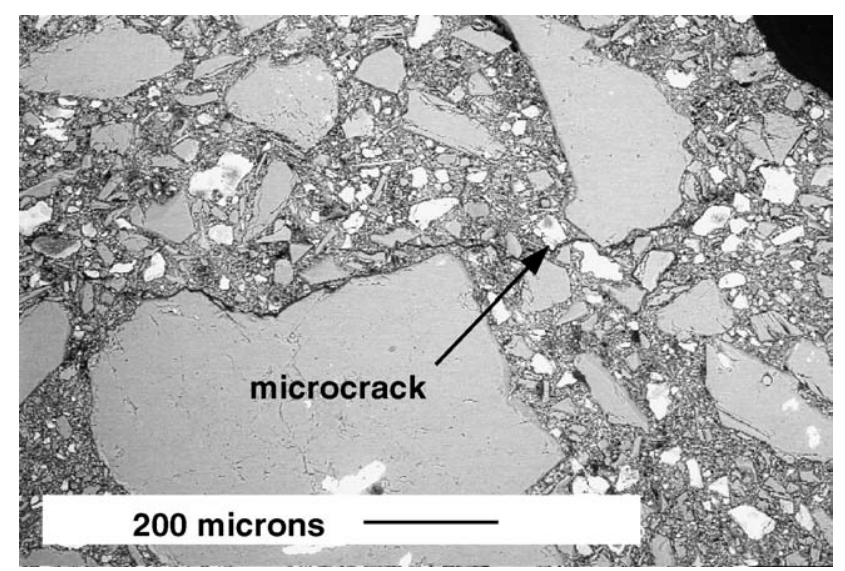

Fig. 4. Observation of damage in the And-LCC castable after firing at $700^{\circ} \mathrm{C}$ (scanning electron microscopy).

653 resistive furnace with two heating zones and a maximum capacity of $1400^{\circ} \mathrm{C}$. The specimen geometry has been defined to allow tests in the $20-900{ }^{\circ} \mathrm{C}$ temperature range. A reduced cross-section of $30 \mathrm{~mm} \times 25 \mathrm{~mm}$ allows to con-

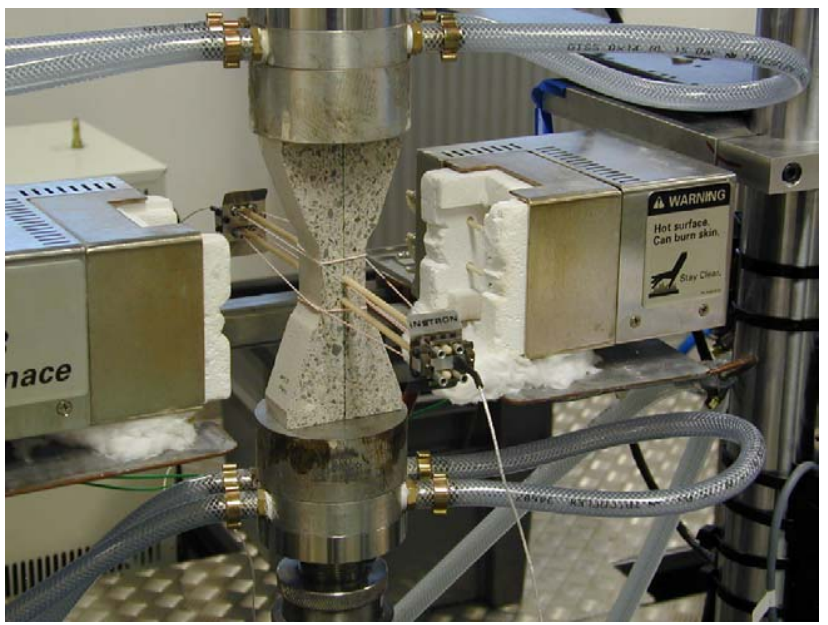

Fig. 5. Tensile test device: zoom on the active parts. centrate the highest stress levels in the hottest area of the specimen. Transversal dimensions of samples are limited by the furnace size. Strain measurements are performed using two high temperature extensometers that are characterized by a $12.5 \mathrm{~mm}$ gauge length. They are placed on two opposite faces of the specimen. Machining by grinding is performed on the two opposite faces that support the extensometers. A parallelism error lower than $0.05 \mathrm{~mm}$ is obtained between these two faces. A particular attention is also paid to obtain the better alignment between the sample axis and the machine loading axis in order to minimize parasitic bending. Monotonic tests and cyclic loading/unloading tests are performed for each temperature configuration with a crosshead displacement velocity of $0.04 \mathrm{~mm} / \mathrm{min}$. This tensile test configuration allows to perform tensile/compression or compression/tensile tests too.

\subsubsection{Compression test}

The tests are performed at room temperature on an INSTRON 4467 electro-mechanical universal testing machine. Samples have a cylindrical geometry and are axially loaded between two metallic plates. They are characterized by a $30 \mathrm{~mm}$ diameter and a $45 \mathrm{~mm}$ height. As for tensile tests samples, after a diamond machining step, a parallelism error lower than $0.05 \mathrm{~mm}$ is obtained between the sample extremities. Two types of loading are considered: monotonic loadings and cyclic loadings-unloadings. The specimens are tested with a crosshead displacement rate of $0.1 \mathrm{~mm} / \mathrm{min}$. The load is recorded as a function of the crosshead displacement that is corrected from the machine stiffness.

\subsubsection{Four points bending test}

For four points bending tests, a specific device installed on a MTS 810 servo-hydraulic universal testing machine is used (Fig. 6). Several works have shown that experimental results of bending tests are very sensitive to the boundary conditions, like the loading contacts and the degrees of freedom of the

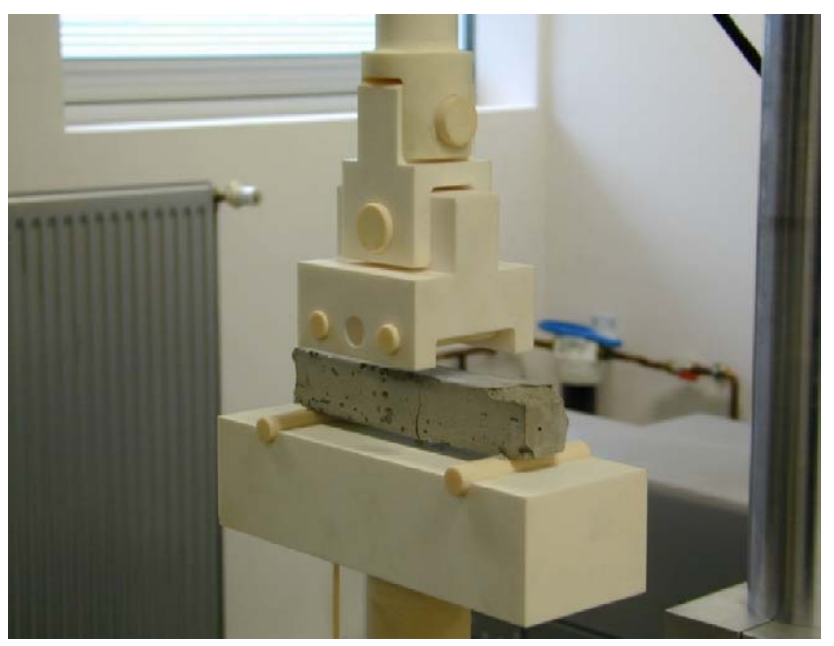

Fig. 6. Four points bending device in the room temperature configuration: zoom on the active parts. 

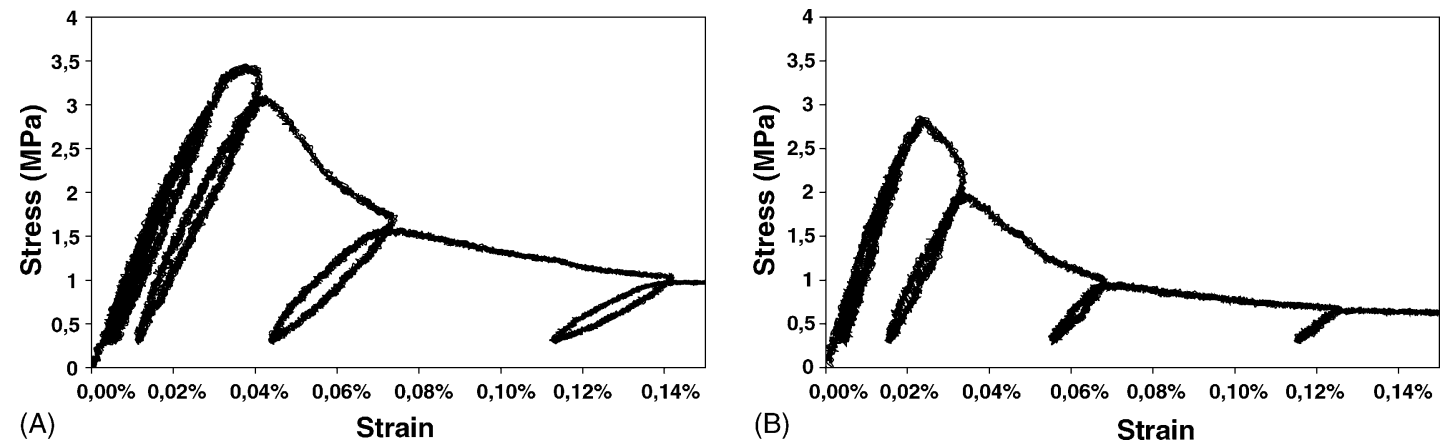

Fig. 7. Tensile test behaviour curves of the FRRC castable after firing at $500{ }^{\circ} \mathrm{C}(\mathrm{A})$ and at $900{ }^{\circ} \mathrm{C}(\mathrm{B})$.

contact supports. ${ }^{16,17}$ As a consequence, some precautions have been taken in order to minimize the error sources that have been previously identified in testing ceramics. Loading is applied with alumina parts. The two lower alumina rollers are $125 \mathrm{~mm}$ spaced and supported by a fixed base. The two upper rollers are $45 \mathrm{~mm}$ spaced and are supported by a free rotation universal joint. Samples have a $150 \mathrm{~mm}$ length and a $25 \mathrm{~mm} \times 25 \mathrm{~mm}$ cross-section. The lower and upper faces of the sample are machined by grinding to obtain a parallelism error lower than $0.05 \mathrm{~mm}$ between these two faces. Measurement of the sample deflection is made by a linear variable displacement transducer (LVDT) coupled with a fine alumina rod that is in contact with the central point of the sample lower face. For high temperature tests, the system is entirely placed in a radiative furnace with a maximum capacity of $1600{ }^{\circ} \mathrm{C}$. Both monotonic tests and loading/unloading cyclic tests have been performed and a constant crosshead displacement velocity of $0.02 \mathrm{~mm} / \mathrm{min}$ was retained.

The material elastic strength theory is applied to calculate the Young's modulus and the nominal strength on the tension sample face. This enable us to compare four points bending curves obtained on different samples, even if sample cross sections are not exactly the same. The nominal strength, $\sigma$ and the Young's modulus, $E$ are calculated as follow:

$\sigma=\frac{3 P(L-l)}{2 b h^{2}}$

$E=\frac{P}{f} \frac{1}{8 b h^{3}}(L-l)\left(2 L^{2}+2 L l+l^{2}\right)$

where $P$ is the applied load; $b$ and $h$ are, respectively the width and the thickness of the specimen; $L$ and $l$ are the distances between the lower and the upper loading rollers and $f$ is the sample deflection.

\section{Mechanical properties}

\subsection{Tensile test results}

For the FRRC, results of tensile tests performed both on a $500{ }^{\circ} \mathrm{C}$ fired FRRC specimen and on a $900{ }^{\circ} \mathrm{C}$ fired specimen are shown in Fig. 7. Generic comments can be made to de- scribe this room temperature tensile behaviour. At the beginning of the first loading and during the first loading/unloading cycle, a linear elastic behaviour is observed. When the stress level increases, the behaviour moves to a non-linear one. This is due to microcracking damage processes that occur in the FRRC. At the stress peak, one or several macrocracks appear in the tensile test sample. The behaviour moves then to a softening part, because of the presence of fibres that bridge the macrocracks. During the application of the loading/unloading cycles, permanent strains and hysteresis loops are measured. This must be related to the energy loss by internal friction in the microcracks.

Focussing on the beginning of the tests, the Young's modulus can be calculated by a numerical interpolation of the linear part of the behaviour curves. A 11.5 GPa Young's modulus value is calculated on the strain-stress curve of the $500^{\circ} \mathrm{C}$ fired FRRC and a 13.0 GPa Young's modulus value is determined on the strain-stress curve of the $900^{\circ} \mathrm{C}$ fired FRRC.

For the And-LCC castable, an example of a tensile test result performed on a $700{ }^{\circ} \mathrm{C}$ fired specimen is shown in Fig. 8 . As described in a previous paper, ${ }^{14}$ an important damage develops during the first thermal cycle at such a temperature, and particularly during the cooling stage. This thermal damage is a consequence of the differential dilatometric behaviours of the matrix and of the aggregates. The behaviour curve of Fig. 8 is characterized by a very restricted linear do-

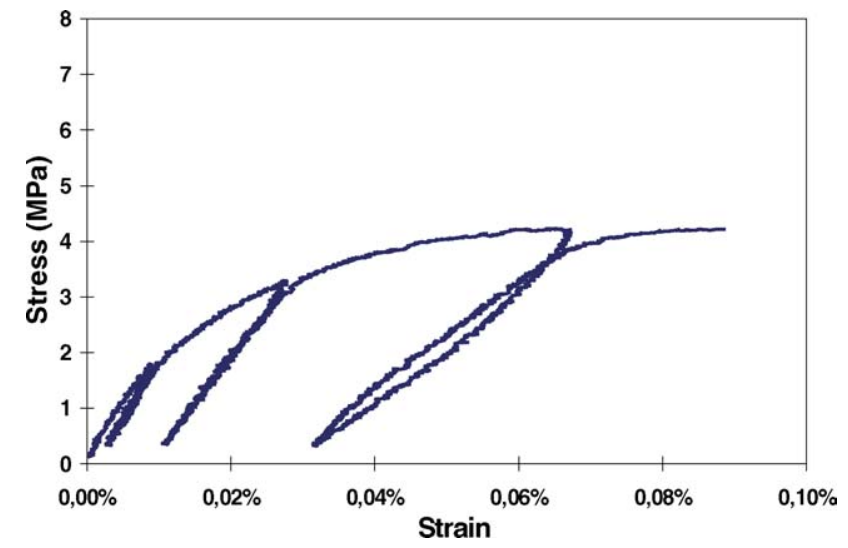

Fig. 8. Tensile test behaviour curve of the And-LCC castable after firing at $700^{\circ} \mathrm{C}$. 

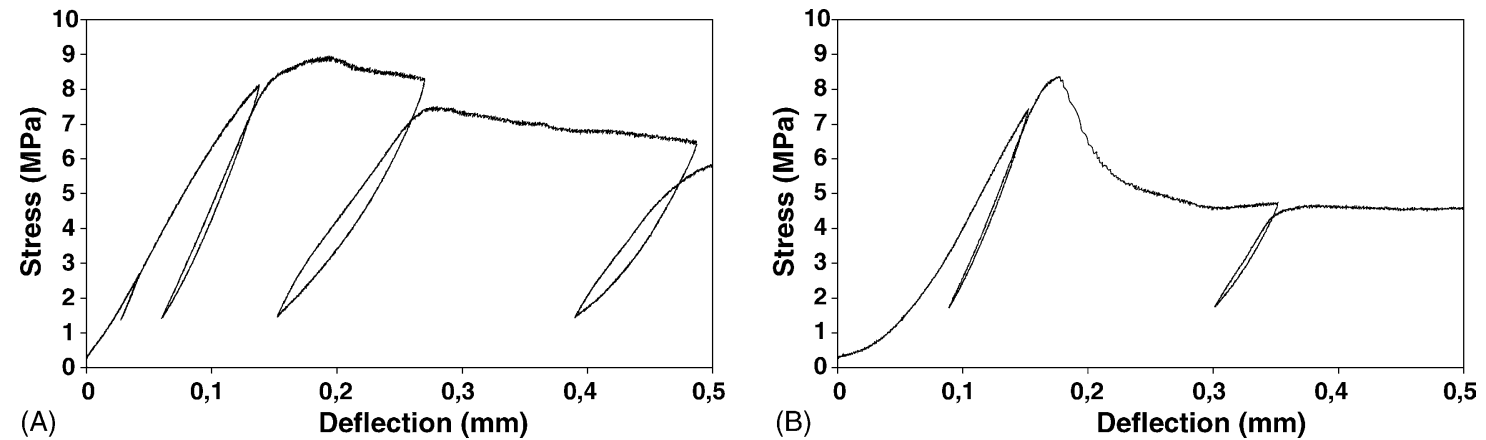

Fig. 9. Four point bending behaviour curves of the FRRC refractory castable after firing at $500{ }^{\circ} \mathrm{C}(\mathrm{A})$ and at $900^{\circ} \mathrm{C}(\mathrm{B})$.

main at the beginning of the first loading. An initial Young's modulus value of $21.0 \mathrm{GPa}$ can be measured. The Young's modulus values calculated on the three successive loadingunloading loops are respectively, of 20.0,16.5 and $11.5 \mathrm{GPa}$. This regular decrease in the Young's modulus values coupled with the increase of the permanent strain levels and of the loop opening indicates a damage increase in the microstructure. Such phenomenon have already been observed in other classes of refractory castables. ${ }^{9,18,19}$

\subsection{Four points bending test results}

Fig. 9 shows four points bending curves with successive loading/unloading cycles for the FRRC castable that has been fired at 500 or at $900{ }^{\circ} \mathrm{C}$. As for tensile tests curves, a nonlinear behaviour is observed but some specificities have appeared on these four points bending curves. The first one deals with the non linear part at the early beginning of the test. Similar phenomena have been previously observed and attributed to the installation of the contacts between the specimen and the loading rollers. ${ }^{9}$ Then the behaviour moves to a linear part, on which a $8.0 \mathrm{GPa}$ Young's modulus value has been calculated in the both cases of Fig. 9. The second specificity deals with the comparison of the linear domain of the first loading and of the loading/unloading loops that are performed in this domain. Calculating the Young's modulus on the first loading/unloading loop leads to a $10.5 \mathrm{GPa}$ value for the $500{ }^{\circ} \mathrm{C}$ fired FRRC and to a $11.5 \mathrm{GPa}$ value for the $900{ }^{\circ} \mathrm{C}$ fired one (Table 1). In both cases, a difference is observed between the Young's modulus values that are calculated on the first loading and on the first loading/unloading loop. It must be noticed that the highest values are obtained for the loading/unloading loops. In the case of a linear elastic behaviour, this second specificity is unexpected for four points bending tests. For highest stress levels, the behaviour moves then to a non linear domain indicating that damage processes occur in the materials. As for tensile tests, a peak stress is reached when macrocracking starts to occur.

A behaviour curve example is given on Fig. 10 for the AndLCC castable after a $700{ }^{\circ} \mathrm{C}$ firing. This four points bending behaviour is similar to the FRRC castable one and the same specificities are particularly observed. The early beginning of the curve exhibits a non linear part and the behaviour moves then to a linear domain. Loading/unloading cycles that have been performed in this linear domain are again characterized by a higher slope than the one of the first loading. Thus, a 8.0 GPa Young's modulus value has been determined on the linear part of the first loading against a $12.0 \mathrm{GPa}$ value on the first loading/unloading loop.

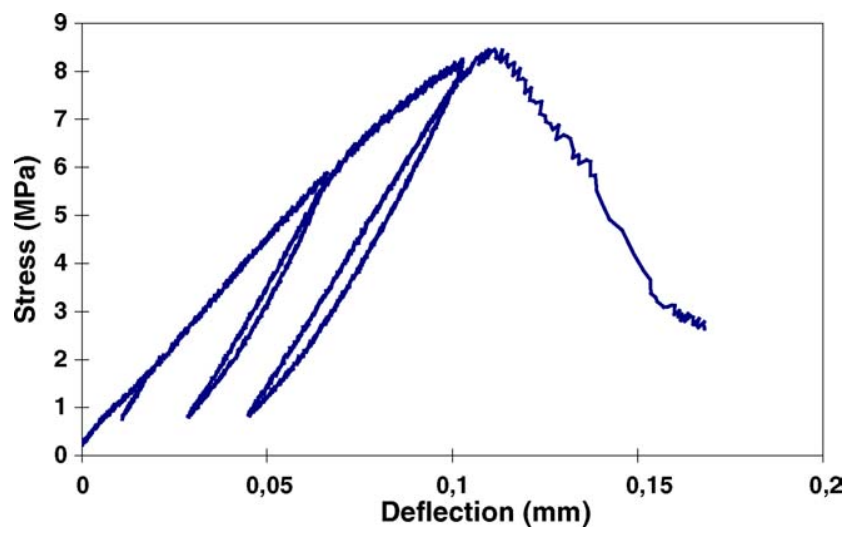

Fig. 10. Four point bending behaviour curve of the And-LCC castable and after firing at $700^{\circ} \mathrm{C}$.

Table 1

Young's modulus values (in GPa) determined from each type of test as a function of the firing temperature and of the considered material

\begin{tabular}{|c|c|c|c|c|}
\hline & & FRRC fired at $500^{\circ} \mathrm{C}$ & FRRC fired at $900^{\circ} \mathrm{C}$ & And-LCC fired at $700^{\circ} \mathrm{C}$ \\
\hline Direct tension & (1st loading) & 11.5 & 13.0 & 21.0 \\
\hline Four points bending & (1st loading) & 8.0 & 8.0 & 8.0 \\
\hline Four points bending & (1st unloading) & 10.5 & 11.5 & 12.0 \\
\hline Compression & (1st loading) & 6.0 & 6.5 & - \\
\hline Compression & (1st unloading) & 10.0 & 10.0 & - \\
\hline
\end{tabular}




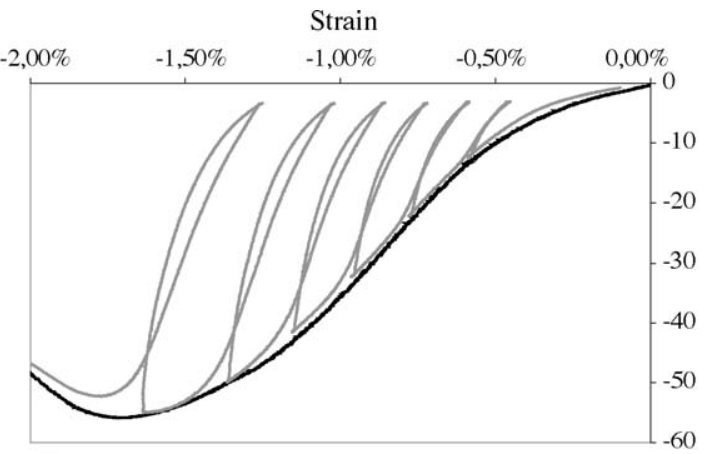

(A)

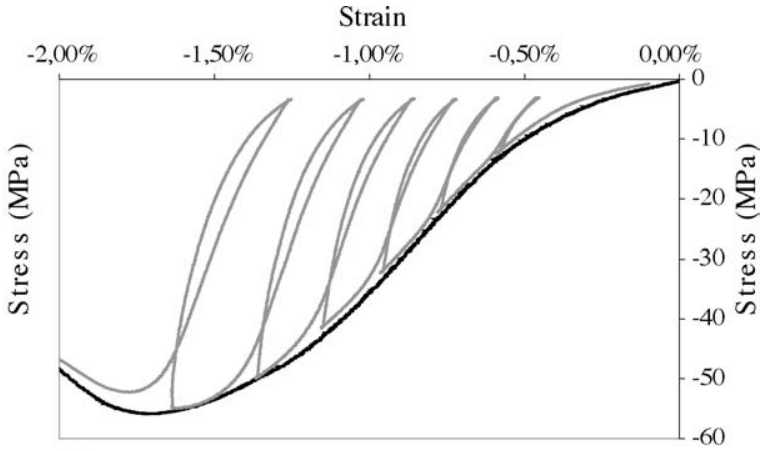

(B)

Fig. 11. Monotonic and cyclic compression behaviour curves of the FRRC castable after firing at $500{ }^{\circ} \mathrm{C}(\mathrm{A})$ and at $900{ }^{\circ} \mathrm{C}(\mathrm{B})$.

\subsection{Compression test results}

Fig. 11 shows compression curves both for monotonic tests and for cyclic tests in the case of the FRRC castable fired at 500 and at $900{ }^{\circ} \mathrm{C}$. For a given firing temperature, the comparison of the monotonic and of the cyclic curves allows to observed the test reproducibility and to conclude that performing cyclic tests does not significantly influence the compression behaviour. The same behaviour description can be made for these compression curves as for the four bending ones. They first starts with a non linear domain before moving to a linear one. As previously observed for tensile and four points bending tests, increasing the stress level induces another non linear domain that is due to the development of damage processes in the material. Furthermore, the two same specificities are still present and particularly the slope difference between the linear part of the first loading and the first loading/unloading loop. As a consequence, discrepancies are obtained between the Young's modulus values that can be determined from these slopes. As an example, in the case of the $900{ }^{\circ} \mathrm{C}$ fired material, a $6.5 \mathrm{GPa}$ value is calculated on the first loading against a $10.0 \mathrm{GPa}$ value on the first loop unloading.

\subsection{Comparison between the various mechanical tests}

The comparison between the behaviour curves in the tension, compression and bending configurations enable us to observe some similarities. During the first loading, a linear domain is obtained for each type of tests and the behaviour then becomes non-linear because of microcracking processes that act in the refractory castables. When the damage threshold is exceeded, evolutions of the loading/unloading loops are noticed. They deal with a decrease of their slope and with an increase of their opening. A peak stress is then observed as soon as the damage processes move to localized ones and generate one or several macrocracks.

But differences are observed between the results of the three considered test types too. Some unexpected ones deal with the characteristics of the linear domain of the first loadings where the material behaviour is assumed to be linear elastic. Table 1 allows to compare the Young's modulus values that could be determined from the different behaviour curves and for different firing cycles. Results show that many factors can influence these Young's modulus values. For such materials, changing the firing temperature leads to microstructural evolutions that can modify their elastic properties and therefore their Young's modulus value. On the other hand, in the linear elastic domain, changing the loading mode or performing loading/unloading cycles should not modify the Young's modulus. Two types of discrepancies are observed in these results. The first one deals with the different Young's modulus values that are obtained for each solicitation mode, even for a given thermal history of the material. The second one deals with the higher Young's modulus values that are determined on the first loading/unloading loop compared to those that are determined on the initial loading when considering four points bending tests and compression tests. The discussion of the present paper will be devoted to this discrepancies and to their explanation.

\section{Discussion on the Young's modulus determination}

\subsection{Case of the four points bending test}

The bending and the compression tests will be considered separately in order to identify the mechanisms that lead to the observed Young's modulus discrepancies under these two loading modes. In the four points bending configuration, during the first loading, the contact under each loading roller is of a hertzian type. Such local effects at the roller/sample contacts are known to influence the deflection measurement and to generate non-linear behaviours for weak loadings in the case of refractory castables. ${ }^{9}$ Even if such mechanisms occur during bending tests on refractory castables, it remains difficult to explain why the Young's modulus values determined on loading/unloading loops are higher than those determined on the linear part first loading. In order to obtain more details on the effects of such a contact mode, a specific test has been developed and performed. It consists of an indentation test with a lineic contact, as described on Fig. 12. It allows to characterize the refractory castable behaviour in the contact area between the sample and the roller. Tests were carried out on $25 \mathrm{~mm} \times 25 \mathrm{~mm} \times 25 \mathrm{~mm}$ cubic samples for each consid- 


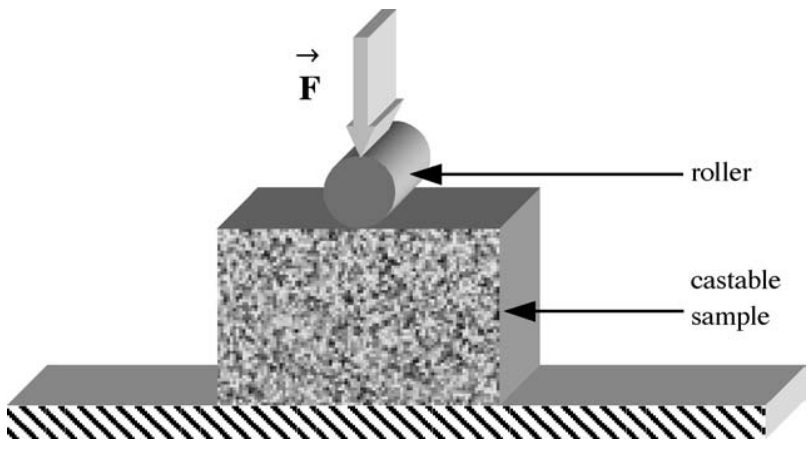

Fig. 12. Principle of the lineic indentation test.

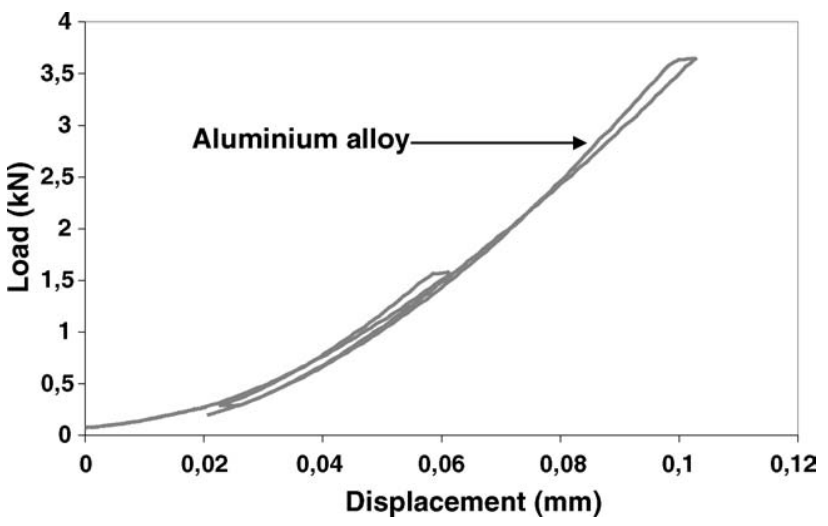

Fig. 13. Lineic indentation test: behaviour curve of an AU4G aluminium alloy.

ered material. Loading and unloading rates are the same as those retained for the four points bending tests and the results are plotted as the variations of the applied load versus the crosshead displacement. Such a behaviour curve is given in Fig. 13 in the case of an AU4G aluminium alloy.

In agreement with the theory of Hertz applied to an elastic material, the behaviour is non linear for weak loadings and gradually tends to a linear asymptotic one when the load level increases. Loading/unloading cycles show that this behaviour is quite reversible for this metallic alloy. It is almost the case for the $110^{\circ} \mathrm{C}$ dried refractory castables (Fig. 14). Nevertheless, results obtained on these dried samples, tend to indicate an increase of the slope of the unloading curves compared to the slope of the first loading as well as permanent strains are measured at low load levels. These effects are clearly enhanced when the refractory castables have been previously fired at high temperature. As an example, in the case of the FRRC castable, results indicate that the higher the firing temperature of the castable is, the higher the slope changes and the more permanent strain amplitudes are. In other words, it could be mentioned that the higher the initial damage level of the castable is, the higher the slope changes and the permanent strain amplitudes are. The same trend is observed for the And-LCC castable when comparing the behaviour curves of a $110^{\circ} \mathrm{C}$ dried sample and of a $700{ }^{\circ} \mathrm{C}$ fired one.

In the case of four point bending tests performed on samples that have been damaged during a firing thermal cycle, the measurement of the beam deflection is influenced by local permanent strains that appear at the roller/sample contacts since low load levels. That is the reason why important similarities are observed between the load-displacement curves of lineic indentation tests and those of four point bending tests. Thus, the measured deflection values do not only reflect the elastic bending of the beam. As a consequence, the Young's modulus values that are calculated from the linear part of the first loading of the four points bending curves are only apparent ones and they are lower than those determined on the tensile test curves. In previous works, Schmitt et al. ${ }^{10}$ have measured a 25.2 GPa Young's modulus value during tensile tests performed on a magnesia-carbon refractory. For the same material, they have determined a $18.6 \mathrm{GPa}$ value when considering the load/deflection curve of three points bending tests. It can be considered that the same trend is observed than for the materials considered in the present paper. Moreover, it is interesting to notice that these authors have determined the Young's modulus from the measurements of strain gauges too. These gauges were glued on the three points bending beam and on the face that is mainly subjected to tension stresses. In that case, the obtained Young's modulus value is of $24.0 \mathrm{GPa}$ and is almost equal to the Young's modulus determined on direct tensile test curves. This result confirms that for refractory castables, the Young's modulus values that are determined on load/deflection curves are underestimated because the beam deflection measurements are influenced by the local phenomena that occur at roller/sample contacts.
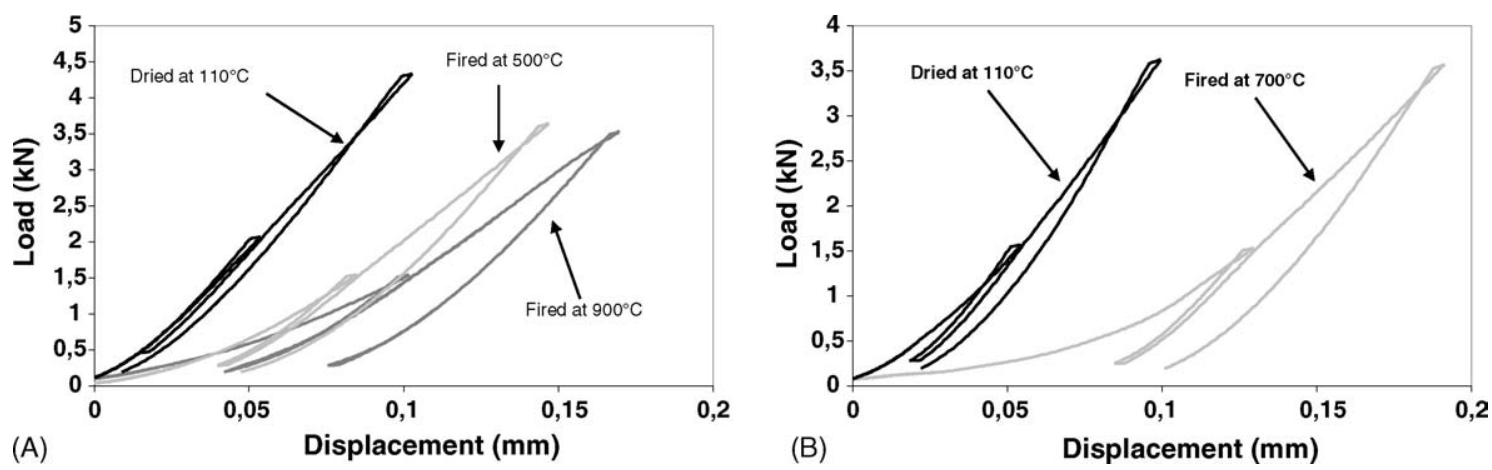

Fig. 14. Lineic indentation test: behaviour curves of the FRRC castable (A), of the And-LCC castable (B), for different firing temperatures. 
In the case of high temperature bending tests, the deflection measurement is the easiest way to obtain data on the strain state of the beam and is often performed. Nevertheless, load/deflection bending curves must be carefully considered in the case of damaged materials. For a given refractory castable, they can give qualitative data on the high temperature behaviour and quantitative ones dealing with the hot modulus of rupture or of other specific strengths. But dealing with the Young's modulus determination and with strain calculations, they can be highly influenced by local phenomena that act at the roller/sample contact.

\subsection{Case of the compression test}

In the case of compression tests, the same discrepancies are observed:

- the Young's modulus values calculated on the linear part of the first loading are low compared with tensile test ones, - the Young's modulus values calculated on the loading/unloading loops are higher than those calculated on the linear part of the first loading.

As for bending tests and in order to obtain more details on the sources of such discrepancies, specific compression tests have been developed and performed too.

First they deal with successive interrupted compression tests that have been carried out on the FRRC castable. They consist of applying a load on a compression sample up to a given stress level that is just below the damage threshold. Load is then totally withdrawn by removing the contact between the loading plates and the sample. The same sequence is run four times on the same sample. Results of such successive compression tests are shown on Fig. 15 for the FRRC castable, both after a $110^{\circ} \mathrm{C}$ drying and after a $500{ }^{\circ} \mathrm{C}$ firing. Considering only the loading curves, results show that the slope of the linear part gets steeper as the sequence number increases. This is particularly true between the two first sequences. Young's modulus values have been calculated by linear interpolation on these linear parts and are given in Table 2.
Table 2

Young's modulus values (in GPa) calculated from the four loadings of successive interrupted compression tests

\begin{tabular}{llc}
\hline & $\begin{array}{l}\text { FRRC sample } \\
\text { fired at } 110^{\circ} \mathrm{C}\end{array}$ & $\begin{array}{l}\text { FRRC sample } \\
\text { fired at } 500^{\circ} \mathrm{C}\end{array}$ \\
\hline First loading & 20.0 & 7.0 \\
Second loading & 25.0 & 16.0 \\
Third loading & 25.0 & 16.5 \\
Fourth loading & 25.0 & 17.0 \\
\hline
\end{tabular}

Between the two first loading curves, a $24 \%$ increase of the Young's modulus is measured for the $110^{\circ} \mathrm{C}$ dried sample whereas a $130 \%$ increase is measured for the $500{ }^{\circ} \mathrm{C}$ fired sample. Thus, the firing cycle appears as enhancing drastically the amplitude of this Young's modulus increase. This could be related to the initial damage state of the material that is higher in the case of the $500{ }^{\circ} \mathrm{C}$ fired sample. It appears that the higher the initial damage level is, the higher the Young's modulus increase is. These successive compression tests show that the difficulty to determine the Young's modulus is enhanced for fired refractory castables.

A second type of compression tests was carried out by gluing the two sample extremities on the loading plates. This configuration allows to minimize interface effects between the sample and the plates and to apply a tensile loading on the sample too. A behaviour curve example is given in Fig. 16A for a FRRC castable fired at $500^{\circ} \mathrm{C}$ and is compared with the behaviour curve of a classical compression test (non-glued sample). In the glued configuration, a linear behaviour is observed in tension and in compression since the beginning of the test. The Young's modulus remains constant between the tension and compression domains and is equal to $11.5 \mathrm{GPa}$. This indicates that the Young's modulus is not intrinsically different under these two loading modes. Furthermore, it can be noticed that this Young's modulus value is the same as the one obtained during direct tensile tests (Table 1).

Up to a stress level close to $-15 \mathrm{MPa}$, the behaviour curve remains linear. Beyond this threshold, the compression behaviour curve moves to an non-linear domain indicating that damage processes occur in the castable. It is now interest-

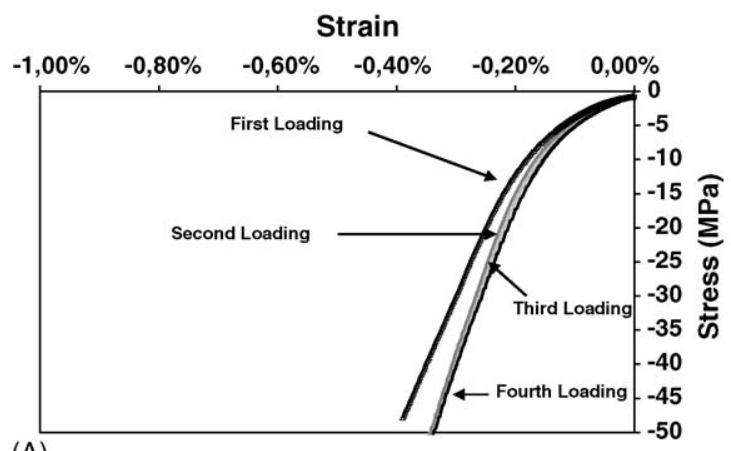

(A)

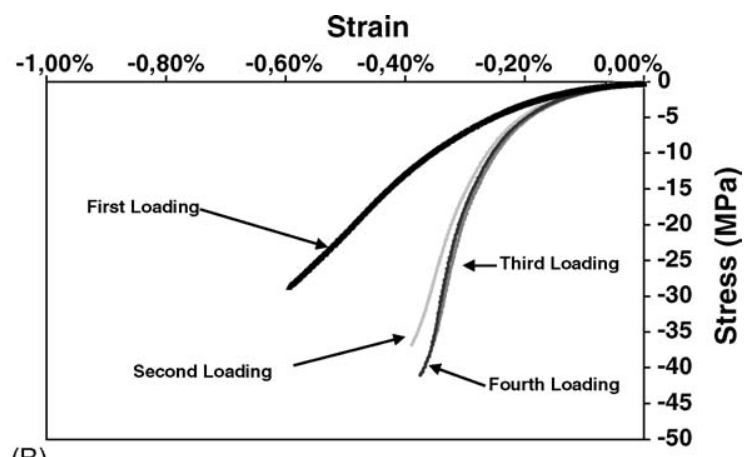

(B)

Fig. 15. Loading behaviour curves of successive compression tests on the FRRC castable after a $110^{\circ} \mathrm{C}$ drying (A) and after a $500{ }^{\circ} \mathrm{C}$ firing (B). 


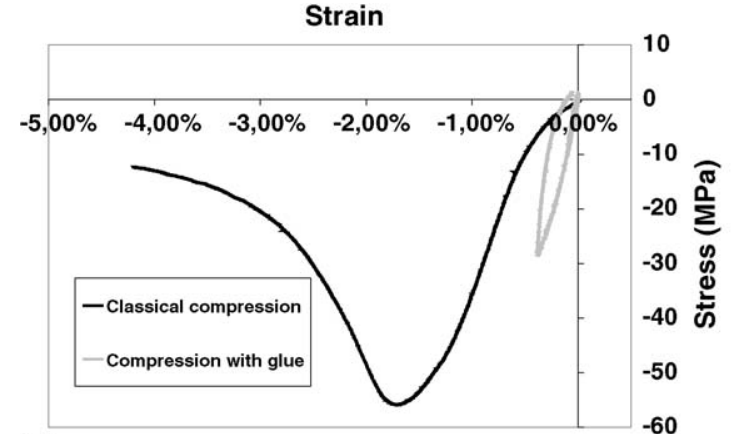

(A)

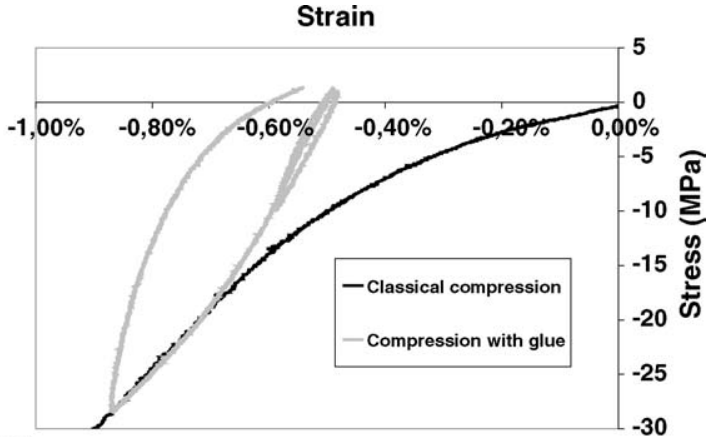

(B)

Fig. 16. Comparison between the results of a classical compression test (without glue at the sample extremities) and the results of a compression test with glue at the sample/plate interface (FRRC after firing at $\left.500^{\circ} \mathrm{C}\right)$.

ing to focus on the comparison between this behaviour curve and the one of a classical compression test (Fig. 16A and B). Fig. 16B allows to see that adding an offset to the strain values of the glued configuration has made it possible to perfectly superpose the high stress domain of the resulting curve with the linear domain of the classical compression test curve. This indicates that damage processes occur in this domain and that the 6.0 GPa Young's modulus value that has been calculated on the classical compression test (Table 1) must be considered as an apparent one. Moreover, concerning the discrepancies between the beginning of these two curves, it can be assumed that local effects can act at the sample/loading plate contacts, as previously observed for four points bending tests. Indeed, in spite of the machining of the sample extremities and the adjustment of the parallelism between the loading plates, there is no certainty that two perfect plane to plane contacts are obtained between the sample extremities and the loading plates.

In order to characterize the influence of such local effects, a third type of compression test has been performed. It consists of introducing by machining a parallelism error between the two sample extremities. During that test, strains have been determined both by the measurements of the crosshead displacement and of the two extensometers that have been previously described. The extensometers have been placed opposite to each other in the middle part of the sample and their gauge length is fifteen times lower than the sample height. Results of this test are shown on Fig. 17. At the beginning of the test, the two behaviour curves obtained from the extensometers are highly divergent. This indicates a tensile state on one side of the sample and a compression state on the opposite one. This is clearly due to the geometric defect that has been voluntarily introduced. It appears that it is necessary to reach a stress level close to $-4 \mathrm{MPa}$ in order to place the whole sample in a compression state. Furthermore, it should be noticed from the loading/unloading cycles that the extensometers, that are located far away from the contact surfaces, do not record permanent strains. On the other hand, the behaviour curve obtained from the crosshead displacement exhibits permanent strains. Similar observations had already been made by Prompt ${ }^{5}$ for compression tests performed on an alumina based refractory castable. Such behaviour discrepancies between local and global strain measurements indicate that many local phenomena occur at the sample/plate contacts and generate the appearance of permanent strains on the global compression curves. As a consequence, the linear domain that is observed on these curves during the first loading is not only due to elastic strains of the sample. As for bending tests, the Young's modulus values that can be calculated in this linear domain are apparent ones.

In the case of compression tests at high temperature, the measurement of the crosshead displacement or of the distance between the two loading plates are the easiest ways to obtain data on the strain state of the sample and is often performed. Nevertheless, the resulting behaviour curves must be carefully considered in the case of damaged materials. As for deflection measurements in bending, local phenomena are active and the global displacement values that can be measured are not only due to the elastic behaviour of the compression sample, even if the apparent damage threshold has not been exceeded.

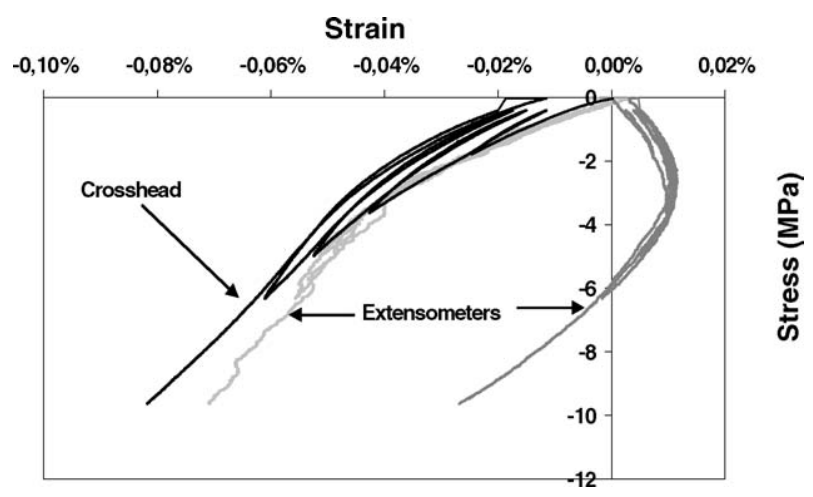

Fig. 17. Result of a compression test with a parallelism defect on the sample: strains have been calculated from the measurements of two extensometers and of the crosshead displacement (FRRC after firing at $500^{\circ} \mathrm{C}$ ). 


\section{Conclusions}

As a conclusion, it is really difficult to determine Young's modulus values of refractory castables by the way of compression or bending tests. That can be done by using strain gauges in the case of room temperature tests but this technique cannot be used at high temperature. As high temperature extensometers are not easy to be used in such test configurations, behaviour curves are often obtained from the measurement of global strains calculated from the beam deflection in bending and from the distance between plates in compression. In bending tests, results have shown that local strain effects take place at the roller/sample contacts and influence the deflection measurement. In compression tests, it is necessary to be aware of the influence of similar contact phenomena that occur at the sample/plate interfaces even after correction of the device stiffness. As a consequence, it is necessary to be extremely careful in the exploitation of behaviour curves obtained under such conditions.

Especially in the case of fired refractory castables, the obtained tensile, compression and bending curves indicate specific behaviours for this type of materials. As already known for such materials, firing heat treatments that are performed in the intermediate temperature range can lead to the development of damage by decohesion and microcracking in the bulk material. For a given mechanical test type, changing the initial damage state will of course modify the behaviour curve and will affect the Young's modulus value. Moreover, it appears from the results of this paper that this damage state plays a major role on the local mechanical behaviour of such refractory castables, particularly in the loading contact areas. Increasing the initial damage state highly increases the amplitude of these local phenomena. Several mechanisms can be evoked to explain them. On the one hand, local micromechanical mechanisms of microcrack closing can influence the behaviour when the loading contact occurs. On the other hand, in the case of the bending tests, a triaxial stress field appears locally under each loading roller. In the case of the lineic indentation test, applying a load of $1 \mathrm{kN}$ leads to an hydrostatic stress close to $138 \mathrm{MPa}$ according to the Hertz theory. ${ }^{20}$ Even if the assumptions of the Hertz theory are not perfectly respected, since the castable behaviour does not remain linear-elastic, this calculation allows to estimate the very high stress levels that are locally generated. Moreover, under such a triaxial compression stress field, it can be assumed that the damaged castables can be compacted. ${ }^{21}$ Furthermore, it can be considered that the firing heat treatment will lead to a decrease of the compaction stress thresholds too.

\section{Acknowledgements}

Authors gratefully acknowledge ACB, Airbus-France, EDF, Hurel-Hispano, Pyromeral Systems, Vesuvius, TRB and the French Ministry for Industry for their technical and financial supports.

\section{References}

1. Boussuge, M., Thermomechanical behaviour: from ceramics to refractories. In Proceedings of the International Conference of Metallurgists COM2004, 2004, pp. 605-616.

2. Schacht, C. A., Thermomecanical behavior of refractories. Key Eng. Mater., 1993, 88, 193-218.

3. Bradt, R. C., Elastic moduli, strength and fracture characteristics of refractories. Key Eng. Mater, 1993, 88, 165-191.

4. Moore, R. E., Significance and utility of refractories test data. In Proceedings of the third Euro-Ceramics, 3, 1993, pp. 185-200.

5. Prompt, N., Etude du comportement thermomécanique d'un béton réfractaire alumineux. Application à une rigole de haut fourneau, Thèse de doctorat, Université Grenoble 1, 2000 (in French).

6. Robin, J.M., Comportement thermomécanique des céramiques réfractaires, Thèse de doctorat, Université de paris 6, 1995 (in French).

7. Robin, J. M., Thermomechanical behaviour of magnesia-carbon refractories. Brit. Ceram. Trans., 1998, 97, 1-10.

8. Nazaret, F., Cutard, T. and Bernhart, G., Thermomechanical behaviour of a fibre-reinforced refractory concrete: tests and FE analysis. In Proceedings of the sixth RILEM Symposium on Fibre Reinforced Concrete (BEFIB 2004), 1, 2004, pp. 689-698.

9. Lemaistre, H., Etude des propriétés thermomécaniques de divers réfractaires, Thèse de doctorat, INSA de Lyon, 1998 (in French).

10. Schmitt, N., Berthaud, Y. and Poirier, J., Tensile behaviour of magnesia carbon refractories. J. Euro. Ceram. Soc., 2000, 20, 2239-2248.

11. Davidovits, J., Geopolymers: man-made rock geosynthesis and resulting development of very early high strength cement. J. Mater. Edu., 1994, 16, 91-139.

12. Cutard, T., Cailleux, E., Lours, P. and Bernhart, G., Structural and mechanical properties of a refractory concrete for superplastic forming tools. Indus. Ceram., 1999, 19, 100-102.

13. Cailleux, E., Cutard, T. and Bernhart, G., Pullout of steel fibres from a refractory castable: experiment and modelling. Mech. Mater., 2005, 37, 427-445.

14. Marzagui, H., Cutard, T., Yeugo Fogain, E., Huger, M., Gault, C. and Prompt, N., Microstructural changes and high temperature mechanical behavior of an andalusite based low cement refractory castable. In Proceedings of the International Conference of Metallurgists COM2004, 2004, pp. 331-345.

15. Marzagui, H. and Cutard, T., Characterisation of microstructural evolutions in refractory castables by in-situ high temperature ESEM. $J$. Mater. Process. Technol., 2004, 155-156, 1474-1481.

16. Quinn, G. D., Flexure strength of advanced structural ceramics: a round robin. J. Am. Ceram. Soc., 1990, 73, 2374-2384.

17. Quinn, G. D. and Morrell, R., Design data for engineering ceramics: a review of the flexure test. J. Am. Ceram. Soc., 1991, 74, 2037-2066.

18. Simonin, F., Olagnon, C., Maximilien, S. and Fantozzi, G., Room temperature quasi-brittle behaviour of an aluminous refractory concrete after firing. J. Europ. Ceram. Soc., 2002, 22, 16-172.

19. Simonin, F., Comportement thermomécanique de bétons réfractaires alumineux contenant du spinelle de magnésium, INSA de Lyon, 2000 (in French).

20. Johnson, K. L., Contact Mechanics. Cambridge University Press, 1985.

21. Burlion, N., Gatuingt, F., Pijaudier-Cabot, G. and Daudeville, L., Compaction and tensile damage in concrete: constitutive modelling and application to dynamics. Comput. Methods Appl. Mech. Eng., 2000, 183, 291-308. 